\title{
Parameter Optimization of Double LCC MCRWPT System Based on ZVS
}

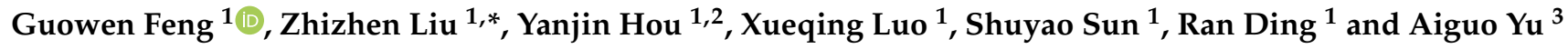 \\ 1 School of Electrical Engineering, Shandong University, Jinan 250061, China; fengguowen0312@163.com (G.F.); \\ houyj@sderi.cn (Y.H.); LXQ15098781097@163.com (X.L.); 202014594@mail.sdu.edu.cn (S.S.); \\ 15098770553@163.com (R.D.) \\ 2 Shandong Provincial Key Laboratory of Biomass Gasification Technology, Energy Institute, Qilu University of \\ Technology (Shandong Academy of Sciences), Jinan 250353, China \\ 3 Qingdao Haidian Electric Co., Ltd., Qingdao 266109, China; 13605320256@126.com \\ * Correspondence: liuzhizhen@sdu.edu.cn
}

Citation: Feng, G.; Liu, Z.; Hou, Y.; Luo, X.; Sun, S.; Ding, R.; Yu, A. Parameter Optimization of Double LCC MCRWPT System Based on ZVS Energies 2021, 14, 5309. https:// doi.org/10.3390/en14175309

Academic Editor: ByoungHee Lee

Received: 19 July 2021

Accepted: 24 August 2021

Published: 26 August 2021

Publisher's Note: MDPI stays neutral with regard to jurisdictional claims in published maps and institutional affiliations.

Copyright: (c) 2021 by the authors. Licensee MDPI, Basel, Switzerland. This article is an open access article distributed under the terms and conditions of the Creative Commons Attribution (CC BY) license (https:/ / creativecommons.org/licenses/by/ $4.0 /)$.

\begin{abstract}
At present, magnetically coupled resonance wireless power transfer (MCRWPT) is the main technology used in electric vehicle wireless power transfer (WPT) due to its advantages of high transmission power and high efficiency. The resonant compensation circuit of the system generally adopts the double LCC (DLCC) structure, which has many capacitor and inductor components. Therefore, it is necessary to optimize the circuit parameters to improve the transmission performance of the system. In this study, the DLCC compensation circuit was modeled and analyzed to lay the foundation for parameter optimization. Secondly, the size parameters of the energy transmitting and receiving coil were determined, and the influence of the change of the primary and secondary compensation inductance on the circuit element stress and output performance was analyzed to determine the optimal compensation inductance value. Thirdly, the realization condition of zero voltage switching (ZVS) was analyzed, the relationship between the input impedance angle of the compensation circuit and the component parameter value was obtained, and a parameter optimization control strategy for realizing ZVS was proposed. Finally, through simulation and experiment, it was concluded that under different power levels, the efficiency of the parameter optimization strategy proposed in this study is as high as $91.86 \%$, increasing by about $1 \%$. Therefore, the research undertaken in this study can promote the development of WPT technology and has certain practical significance.
\end{abstract}

Keywords: MCRWPT; parameter optimization; ZVS; efficiency improvement

\section{Introduction}

The automobile industry is undergoing a comprehensive energy transition, and developing electric vehicles has become a clear direction for numerous countries, such as China, those of Europe, and the United States [1]. Following the advent of intelligent driving, WPT technology has attracted the close attention of numerous scholars and industry researchers due to its advantages, such as safety, reliability, and convenience [2]. MCRWPT technology adds a resonant compensation network to the transmitting and receiving coils, which solves the problems of high leakage inductance and the low power factor of the system [3]. At present, this approach is the main technology for wireless power supply of electric vehicles.

Improving the energy transmission efficiency of the WPT system of electric vehicles is a major challenge in current research. In the power electronic system, the application of soft switching technology is an effective method to improve the system efficiency and reduce the interference [4,5]. The high-frequency inverter circuit commonly used in the electric vehicle WPT system is a voltage-type full-bridge inverter circuit, whose load is connected with the resonance compensation circuit, which creates the conditions for the realization of the soft switch [6,7].

Due to the high operating frequency of the electric vehicle WPT system, which usually reaches the $\mathrm{kHz}$ level, when the compensation network reaches the perfectly resonant state 
(PRS), the diode and MOSFET switching devices in the system cannot be in a perfect soft switching state $[8,9]$. To minimize switching device loss and EMI interference problems, switching devices must be in the ZVS state [10-12]. The literature presents three main realization methods of the inverter ZVS: a control strategy, changing the circuit structure, and parameter optimization.

In previous research $[13,14]$, the PLL phase-locked loop control method is adopted to realize ZVS. In this approach, the input current of the primary side is collected, the phase difference between the voltage and the current is calculated through zero-crossing detection, and the voltage leads the current by a certain phase by adjusting the opening frequency of the inverter for phase locking. The authors of [15] proposed a kind of frequency tracking control method in which the circulation size was detected to determine the working frequency and the resonant inverter circuit was used to determine if there was a large deviation from the natural frequency. Then, the controller was used for frequency conversion and decision-making, and to reduce circulation to an acceptable range, and the frequency was set as the work frequency of the inverter to achieve soft switch control.

The authors of [16] designed a bidirectional WPT system with a ZVS branch with a full-bridge converter. The converter used a branch between switching nodes to provide the ZVS current, and a specially designed modulator was used to obtain an effective ZVS current waveform. The control strategy designed in [17] includes two control loops. Firstly, the $\mathrm{CC}$ or $\mathrm{CV}$ operation mode is realized by the phase-shifting control of the full-bridge inverter. Secondly, a branch composed of the MOSFET and capacitor in series is connected in parallel at both ends of the compensating capacitor on the primary side, and the input phase angle is controlled by changing the compensating capacitor value. The DLCC compensation structure was improved in [18]. ZPA and ZVS are realized by adjusting the compensation capacitance value, and the constant voltage output of the system is realized.

The authors of [19] proposed a method to realize the ZVS switch of the primary side inverter by optimizing the compensation capacitance value of the secondary side. Simulation and experimental results verified the effectiveness of the proposed compensation network and the setting method. The authors of [20] proposed a parameter design method for a DLCC compensation network in the phase-shift process of the full-bridge inverter without an auxiliary circuit, identified and analyzed the conditions for realizing ZVS with a lag switch, and verified the analysis results with a $1 \mathrm{~kW}$ radio energy transmission prototype.

At present, the method of realizing ZVS using an inverter is not accurate. Furthermore, the influence of parameter changes in the compensation circuit on the realization of ZVS has not been considered comprehensively. A complex closed-loop control strategy is difficult to implement because of signal interference and time response. Due to the shift of the transmitting and receiving coil or the change in the load state, it is difficult to realize the ZVS of the switching tube under a wide range of coupling coefficients and output voltages. Therefore, to improve the transmission power and efficiency of the system, it is particularly important to study the WPT system based on ZVS.

This paper is structured as follows. Firstly, the DLCC compensation circuit is modeled and analyzed, and the expressions of current, voltage, and impedance are obtained, thus laying the foundation for parameter optimization. Secondly, the size parameters of the energy transmitting and receiving coils are determined according to relevant standards, and the influence of the change in the primary and secondary compensation inductance on the circuit element stress and output performance is analyzed to determine the optimal compensation inductance value. Thirdly, the realization condition of ZVS is analyzed, the input impedance expression of the compensation circuit is deduced when the component parameter values are changed, the expression of the inverter output current and circuit parameters is established, and the parameter optimization control strategy for realizing ZVS is proposed. Finally, the effectiveness of the control strategy is verified by establishing a Simulink simulation and experimental platforms. 


\section{DLCC MCRWPT System Modeling Analysis}

The DLCC MCRWPT system structure and mutual inductance equivalent circuit are shown in Figures 1 and 2. The system includes a high-frequency inverter circuit, a DLCC resonant compensation circuit (magnetically coupled mechanism), and a rectifier filter circuit. $U_{\text {in }}$ is the input DC voltage; $S_{1}, S_{2}, S_{3}$, and $S_{4}$ are MOSFETs; $L_{f 1}$ and $L_{f 2}$ are the primary and secondary compensating inductors, respectively; $L_{p}$ and $L_{s}$ are the self-inductance of the transmitting coil and the receiving coil, respectively; $\mathrm{M}$ is the mutual inductance, $M=k \sqrt{L_{p} L_{s}}$, where $k$ is the coupling coefficient between $L_{p}$ and $L_{s} ; C_{1}$ and $C_{2}$ are series compensation capacitors of primary and secondary sides, respectively; and $C_{f 1}$ and $C_{f 2}$ are parallel compensation capacitors of primary and secondary sides, respectively. $D_{1}, D_{2}, D_{3}$, and $D_{4}$ are rectifying diodes; $C_{0}$ represents filtering capacitors of the rectifying circuit; $R_{L}$ is the load; and $R_{e q}$ is the equivalent load on the secondary side, where $R_{e q}=8 R_{L} / \pi^{2} \cdot u_{1}$ and $u_{2}$ are the input and output voltages of the resonant network, respectively; $i_{f 1}$ and $i_{f 2}$ are the input and output currents of the resonant network, respectively; $i_{p}$ and $i_{s}$ are the transmitting coil and receiving coil currents, respectively.

$$
\left\{\begin{array}{l}
-\frac{1}{j \omega C_{f 1}} \boldsymbol{I}_{p}+\left(j \omega L_{f 1}+\frac{1}{j \omega C_{f 1}}\right) \boldsymbol{I}_{f 1}=\boldsymbol{U}_{1} \\
-\frac{1}{j \omega C_{f 2}} \boldsymbol{I}_{s}+\left(j \omega L_{f 2}+\frac{1}{j \omega C_{f 2}}\right) \boldsymbol{I}_{f 2}=-\boldsymbol{U}_{2} \\
-\frac{1}{j \omega C_{f 2}} \boldsymbol{I}_{f 2}+\left(j \omega L_{s}+\frac{1}{j \omega C_{2}}+\frac{1}{j \omega C_{f 2}}\right) \boldsymbol{I}_{s}=j \omega M \boldsymbol{I}_{p} \\
-\frac{1}{j \omega C_{f 1}} \boldsymbol{I}_{f 1}+\left(j \omega L_{p}+\frac{1}{j \omega C_{1}}+\frac{1}{j \omega C_{f 1}}\right) \boldsymbol{I}_{p}=j \omega M \boldsymbol{I}_{s}
\end{array}\right.
$$

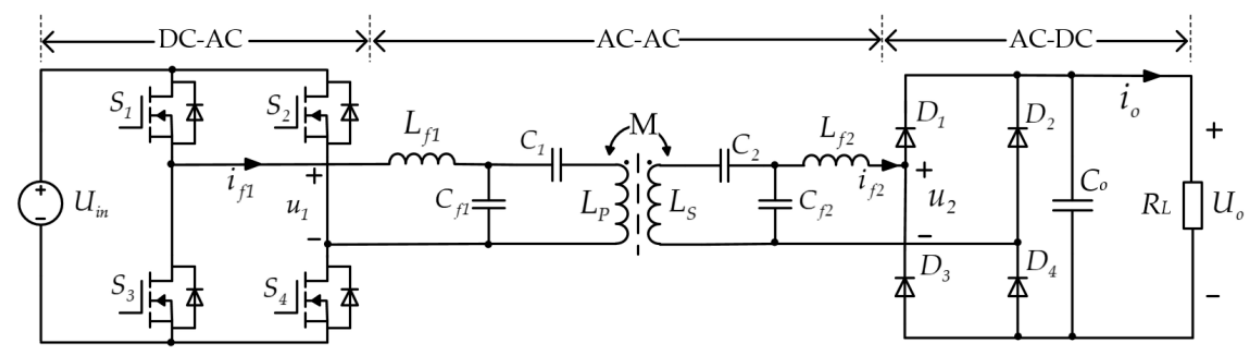

Figure 1. DLCC WPT system structure diagram.

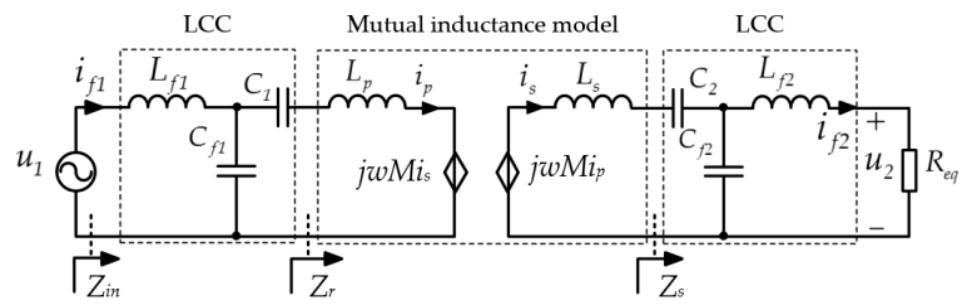

Figure 2. Mutual inductance equivalent circuit of the DLCC WPT system.

Ignoring the parasitic resistances of the capacitor and inductor, and the high-order harmonic components of the voltage of the resonant network, Equation (1) is established according to the mutual inductance equivalent circuit of the system.

The conditions of the full resonance state of the double LCC compensation circuit are as follows:

$$
\begin{gathered}
\omega_{0}^{2} L_{f 1} C_{f 1}=\omega_{0}^{2} L_{f 2} C_{f 2}=1 \\
\omega_{0}^{2}\left(L_{p}-L_{f 1}\right) C_{1}=\omega_{0}^{2}\left(L_{s}-L_{f 2}\right) C_{2}=1
\end{gathered}
$$


In the above equation, $\omega_{0}$ is the resonant angular frequency. According to Equations (1)-(3), we can obtain:

$$
\left\{\begin{array}{l}
\boldsymbol{I}_{f 1}=j \omega_{0}{ }^{3} M C_{f 1} C_{f 2} \boldsymbol{U}_{2}=\omega_{0}{ }^{6} C_{f 1}{ }^{2} C_{f 2}{ }^{2} M^{2} R_{e q} \boldsymbol{U}_{1}=\frac{M^{2} \boldsymbol{U}_{1} R_{e q}}{\omega_{0}^{2} L_{f 1}{ }^{2} L_{f 2}{ }^{2}} \\
\boldsymbol{I}_{p}=-j \omega_{0} C_{f 1} \boldsymbol{U}_{1}=\frac{\boldsymbol{U}_{1}}{j \omega_{0} L_{f 1}} \\
\boldsymbol{I}_{s}=j \omega_{0} C_{f 2} \boldsymbol{U}_{2}=\omega_{0}{ }^{4} C_{f 1} C_{f 2}{ }^{2} M R_{e q} \boldsymbol{U}_{1}=\frac{M \boldsymbol{U}_{1} R_{e q}}{\omega_{0}{ }^{2} L_{f 1} L_{f 2}{ }^{2}} \\
\boldsymbol{I}_{f 2}=-j \omega_{0}{ }^{3} M C_{f 1} C_{f 2} \boldsymbol{U}_{1}=\frac{M \boldsymbol{U}_{1}}{j \omega_{0} L_{f 1} L_{f 2}}
\end{array}\right.
$$

According to Equation (4), $i_{p}$ and $i_{f 2}$ have independent of the load, and the system has a constant current output characteristic. The output power is as follows:

$$
P_{o}=\frac{M^{2} U_{1}^{2} R_{e q}}{\omega_{0}^{2} L_{f 1}^{2} L_{f 2}{ }^{2}}
$$

According to Figure 2, the total input impedance $Z_{i n}$, the equivalent impedance $Z_{S}$ of the secondary side, and the reflection impedance $Z_{r}$ converted from the secondary side to the primary side of the DLCC compensation circuit are, respectively:

$$
\left\{\begin{array}{l}
Z_{i n}=j \omega L_{f 1}+\frac{1}{j \omega C_{f 1}} / /\left(j \omega L_{p}+\frac{1}{j \omega C_{1}}+Z_{r}\right) \\
Z_{s}=j \omega L_{s}+\frac{1}{j \omega C_{2}}+\frac{1}{j \omega C_{f 2}} / /\left(j \omega L_{f 2}+R_{e q}\right) \\
Z_{r}=\frac{\omega^{2} M^{2}}{Z_{s}}
\end{array}\right.
$$

According to the above analysis, it can be concluded that the output characteristics of the DLCC WPT system are mainly related to the parameters of the compensation circuit elements, the coupling coefficient of the transmitting and receiving coils, and the secondary side load. In the following, we optimize the parameters of the system so that the system has a good output characteristic and driving load capacity.

\section{Inductance Parameter Optimization Analysis}

In this paper, according to the relevant standards of SAE J2954-2020 and GB/T3877, the magnetically coupled mechanism was selected, as shown in Figure 3, and its 3D model was established based on ANSYS EM.

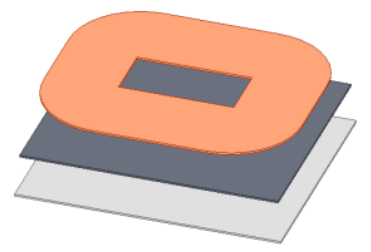

(a)

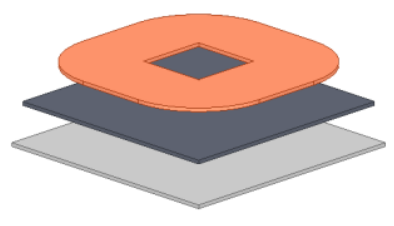

(b)

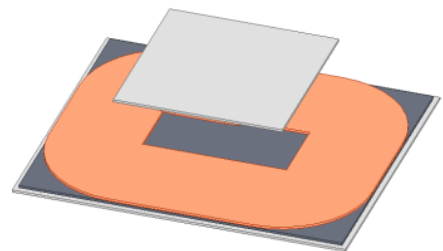

(c)

Figure 3. Diagram of magnetically coupled mechanism: (a) transmitting terminal; (b) receiving terminal; (c) magnetically coupled structure.

In the figure, the orange portion is the energy transfer coil, the black plate represents the ferrite core, and the gray area is the aluminum magnetic shielding layer. The specific geometric parameters of the model are shown in Table 1 . In the case that the energy transfer coil is completely aligned (the distance is $20 \mathrm{~cm}$ ), the simulation results show that the coupling coefficient $k$ is about 0.2 .

The parameters of the DLCC line compensation circuit are generally determined as follows: firstly, the output power level is determined, and the $L_{p}$ and $L_{s}$ are set appropriately. Then the maximum coupling coefficient is determined, and the compensation inductance $L_{f 1}$ and $L_{f 2}$ are determined according to Equation (7). Finally, the compensation capacitance 
is determined according to the resonant condition and the system frequency. The basic parameters of the radio energy transmission system in this paper are shown in Table 2.

$$
L_{f 1}=L_{f 2}=\sqrt{\frac{k U_{1}}{\omega_{o}} \sqrt{\frac{L_{P} L_{S} R_{e q}}{P_{o}}}}
$$

Table 1. Model size of magnetically coupled mechanism.

\begin{tabular}{cccc}
\hline Parameters & Value $\mathbf{( m m )}$ & Parameters & Value (mm) \\
\hline External diameter of transmitting coil & $650 \times 500$ & External diameter of receiving coil & $320 \times 320$ \\
Inner diameter of transmitting coil & $140 \times 290$ & Inner diameter of receiving coil & $100 \times 100$ \\
Radius of transmitting coil fillet & 180 & Radius of receiving coil fillet & 110 \\
The thickness of the coil & 5 & The thickness of the magnetic core & 5 \\
\hline
\end{tabular}

Table 2. Basic parameters of the MCRWPT system.

\begin{tabular}{ccc}
\hline Parameters & Symbol & Value \\
\hline DC supply voltage [V] & $U_{i n}$ & 400 \\
Transmitter coil inductance $[\mu \mathrm{H}]$ & $L_{p}$ & 48.5 \\
Receiver coil inductance[ $\mu \mathrm{H}]$ & $L_{s}$ & 39 \\
Coupling coefficient & $k$ & 0.2 \\
Resonant frequency [kHz] & $f$ & 85 \\
Output power rating [kW] & $P_{o}$ & 7.7 \\
Output voltage [V] & $U_{o}$ & $200-450$ \\
Output current [A] & $I_{o}$ & 17.1 \\
\hline
\end{tabular}

Let $L=L_{f 1}=L_{f 2}, L_{f 1} \times L_{f 2}=L^{2}$; this indicates that the values of $L_{f 1}$ and $L_{f 2}$ are not unique, and are defined as:

$$
L_{f 1}=\sigma L, L_{f 2}=\frac{1}{\sigma} L
$$

In theory, $L_{f 1}$ and $L_{f 2}$ can be reconfigured by changing the value of $\sigma$, assuming that the basic parameters of the system are constant and ensuring that $L$ is constant. According to the above analysis, each $\sigma$ corresponds to a different set of topological parameters. Therefore, the DLCC compensation circuit can be reconfigured by adjusting the value of $\sigma$ without changing the basic system parameters. Next, the transmission characteristics of the MCRWPT system under different $\sigma$ conditions are analyzed to determine the optimal value range of $\sigma$.

\subsection{Stress Analysis of DLCC Compensation Circuit Elements}

The analysis of the voltage and current stress of the capacitor and the inductor resonant element is a factor that must be considered in compensation circuit design. Excessive voltage and current stress may increase the power loss of the element, affect the energy transmission efficiency of the system, and even damage the equipment. According to Table 2 and Equation (8), five groups of values of circuit elements under different values of $\sigma$ are shown in Table 3.

Table 3. Basic parameters of DLCC circuit elements under different $\sigma$ values.

\begin{tabular}{ccccccc}
\hline \multirow{2}{*}{$\sigma$} & \multicolumn{7}{c}{ Parameters } \\
\cline { 2 - 6 } & $\mathbf{L}_{f \mathbf{1}}[\mu \mathbf{H}]$ & $\mathbf{L}_{f \mathbf{2}}[\mu \mathbf{H}]$ & $\boldsymbol{C}_{\mathbf{1}}[\mu \mathbf{H}]$ & $\boldsymbol{C}_{\mathbf{2}}[\mu \mathbf{H}]$ & $\boldsymbol{C}_{f \mathbf{1}}[\mu \mathbf{H}]$ & $\boldsymbol{C}_{f \mathbf{2}}[\mu \mathbf{H}]$ \\
\hline 0.8 & 16.64 & 25.73 & 109.42 & 264.20 & 213.01 & 136.31 \\
0.9 & 18.52 & 22.84 & 116.94 & 216.95 & 189.32 & 153.49 \\
1.0 & 20.58 & 20.58 & 125.57 & 190.33 & 170.36 & 170.36 \\
1.11 & 22.84 & 18.52 & 136.63 & 171.18 & 153.49 & 189.32 \\
1.25 & 25.73 & 16.64 & 153.97 & 155.54 & 136.31 & 213.01 \\
\hline
\end{tabular}


According to Equations (4) and (8), and in combination with the parameters in Tables 2 and 3, the variation in voltage and current stress of each element of the DLCC compensation circuit with output power under different $\sigma$ values is plotted, as shown in Figure 4 . The current $I_{p}$ flowing through the $L_{p}$ and the $I_{f 2}$ of the compensation circuit are constant and independent of the output power, which also verifies the constant current output characteristic of the DLCC circuit structure. $I_{f 1}, I_{s}, I_{C f 1}, I_{C f 2}, U_{s}, U_{C f 1}, U_{C f 2}, U_{C 2}$, and $U_{f 1}$ increase with the increase in output power. Under the same output power condition, $I_{f 1}$ and $I_{f 2}$ do not change with the change in $\sigma$, indicating that the value of $\sigma$ does not affect the input and output current characteristics of the double LCC compensation circuit. $I_{p}, I_{C f 1}$, $U_{p}, U_{C 1}, U_{C f 2}$, and $U_{f 2}$ decrease gradually with the increase in $\sigma$, whereas $I_{s}, I_{C f 2}, U_{s}, U_{C f 1}$, $U_{C 2}$, and $U_{f 1}$ increase gradually. Relatively speaking, the voltage on $C_{f 1}$ and $C_{f 2}$ does not vary significantly with $\sigma$, whereas the voltage on $C_{1}$ and $C_{2}$ varies considerable with $\sigma$; thus, the reasonable choice of $\sigma$ should be based on the voltage limit of the resonant capacitor. In addition, as the most important component of the MCRWPT system, the magnetically coupling mechanism has a decisive influence on the transmission power and efficiency of the system, and the power loss of this component is an important contributor to the total loss of the system. The loss of the magnetically coupling mechanism is comprised mainly of the coil loss. $I_{p}$ and $I_{s}$ directly determine the size of the coil loss. Therefore, a reasonable choice of the $\sigma$ value can reduce the power loss.

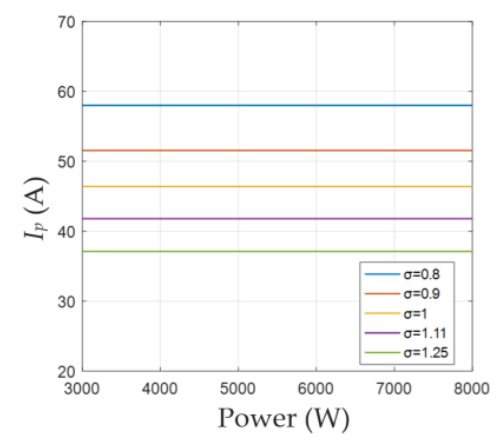

(a)

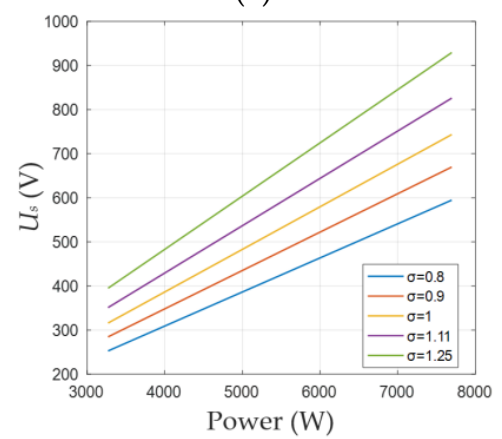

(d)

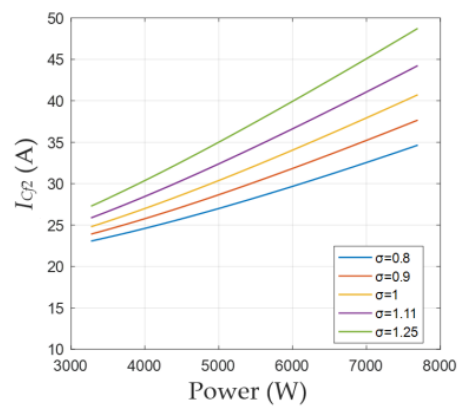

(g)

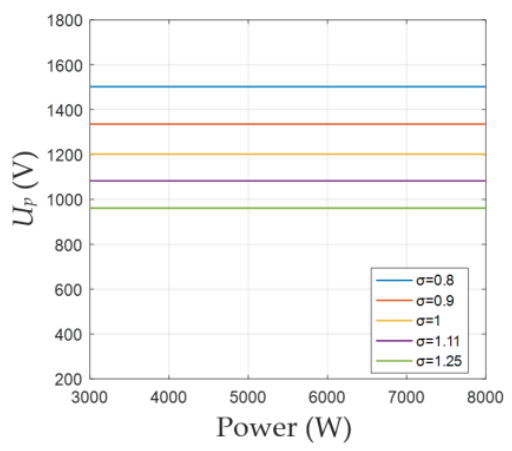

(b)

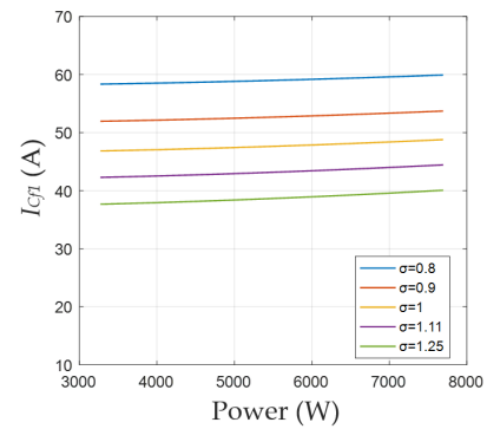

(e)

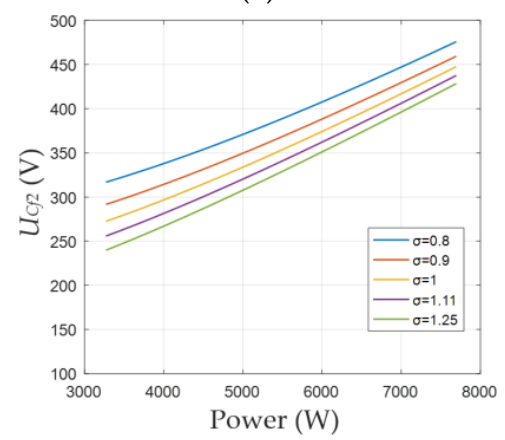

(h)

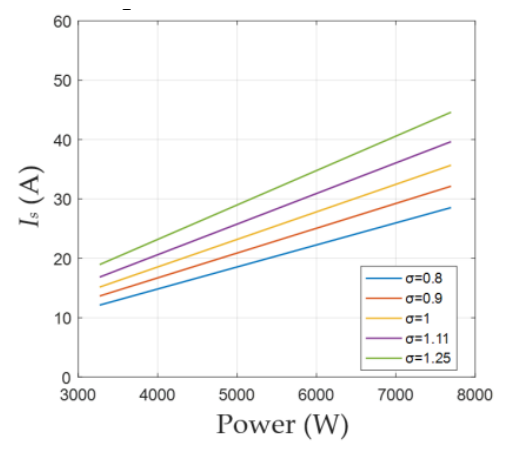

(c)

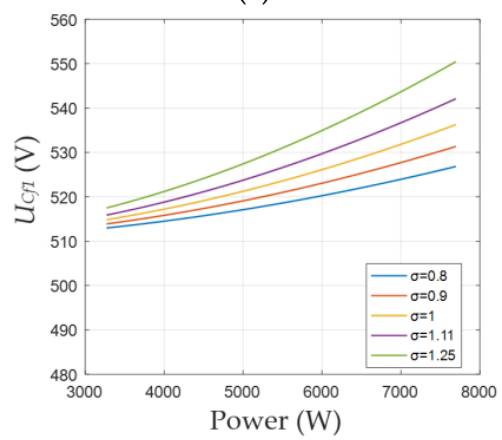

(f)

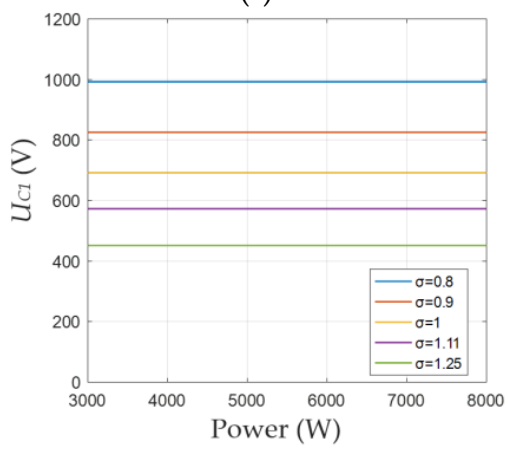

(i)

Figure 4. Cont. 


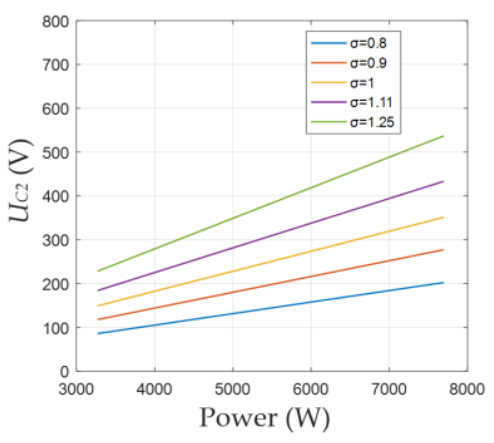

(j)

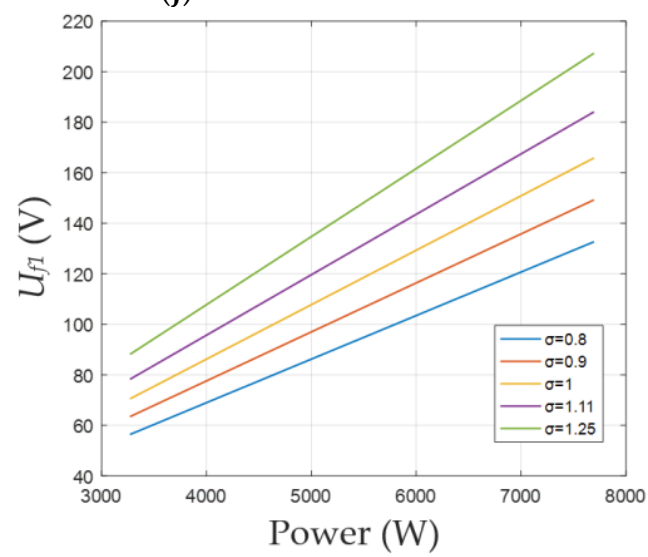

(m)

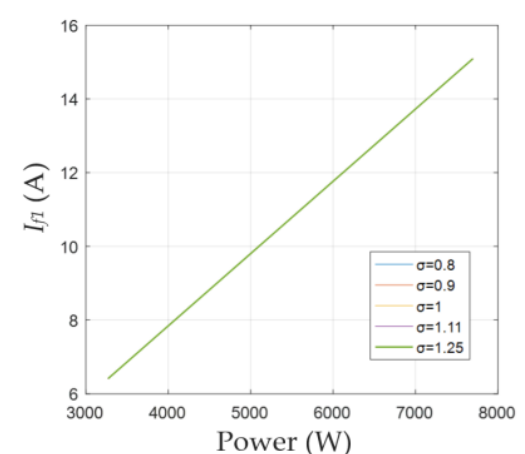

(k)

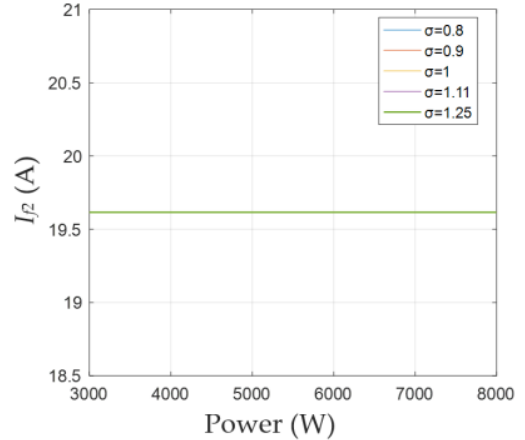

(l)

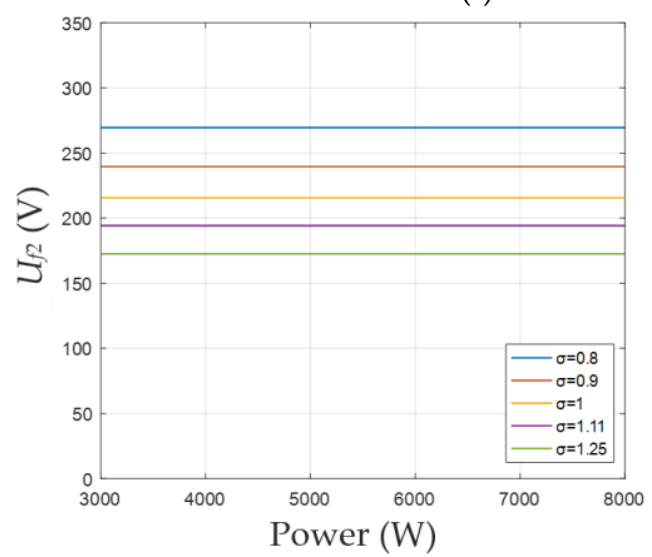

(n)

Figure 4. The voltage and current stress of the components of the double LCC compensation circuit varies with the output power under different $\sigma$ values: (a) $I_{p} ;$ (b) $U_{p} ;$ (c) $I_{s} ;$ (d) $U_{s} ;(\mathbf{e}) I_{C f 1} ;(\mathbf{f}) U_{C f 1} ;$ (g) $I_{C f 2} ;(\mathbf{h}) U_{C f 2} ;(\mathbf{i}) U_{C 1} ;(\mathbf{j}) U_{C 2} ;(\mathbf{k}) I_{f 1} ;(\mathbf{l}) I_{f 2}$; (m) $U_{f 1} ;(\mathbf{n}) U_{f 2}$.

\subsection{High-Frequency Harmonic Suppression}

The voltage waveform of the full-bridge inverter circuit is quantitatively analyzed, and the rectangular wave $u_{1}$ with the amplitude of $U_{i n}$ is expanded into Fourier series, which can be obtained as follows:

$$
u_{1}=\frac{4 U_{i n}}{\pi}\left(\sin \omega t+\frac{1}{3} \sin 3 \omega t+\frac{1}{5} \sin 5 \omega t+\cdots+\frac{1}{2 k-1} \sin (2 k-1) \omega t\right)
$$

As can be seen from Equation (9), the output voltage contains abundant odd harmonics. Although the dual LCC compensation circuit only allows specific resonant frequency components to pass through and has an attenuation effect on the harmonic component, the suppression effect of the high-frequency harmonics is not ideal due to the large number of resonant components in the circuit. Normally, higher harmonics increase switching losses. Because harmonic amplitudes above the fifth order are small, only the fundamental frequencies $(85 \mathrm{kHz})$, the third $(255 \mathrm{kHz})$, and the fifth $(425 \mathrm{kHz})$ are considered. According to the relevant parameters in Tables 2 and 3 , the $I_{f 1}$ harmonic content under different $\sigma$ values was simulated in Simulink. As can be seen from Figure 5, with the increase in $\sigma$, the harmonic content of current $I_{f 1}$ was lower. Therefore, to obtain better harmonic suppression performance, the maximum $\sigma$ should be used. 


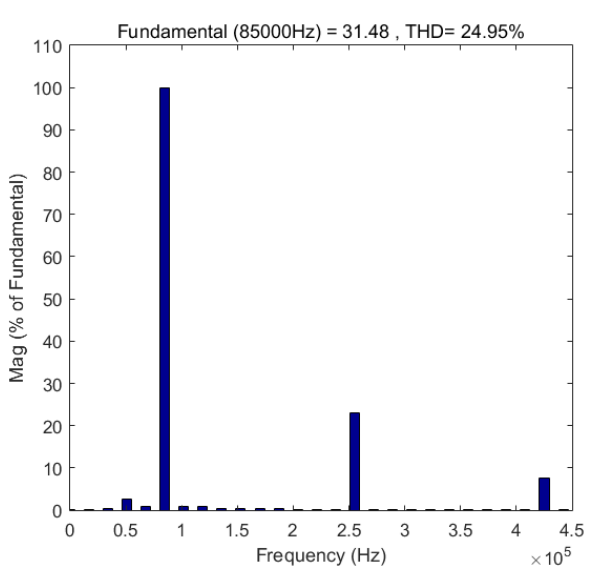

(a)

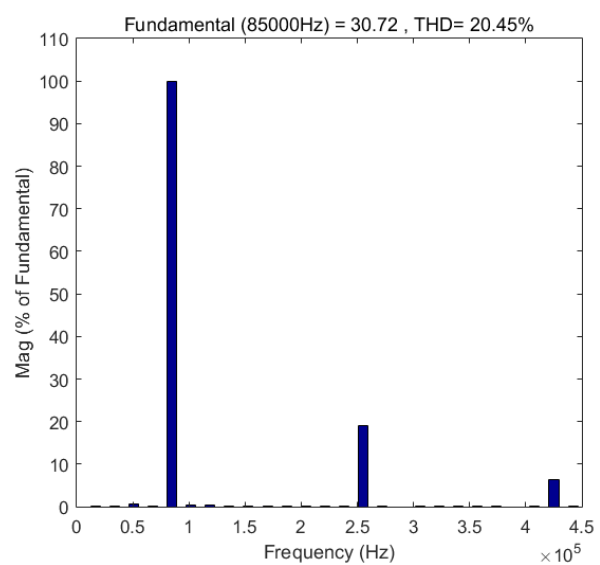

(b)

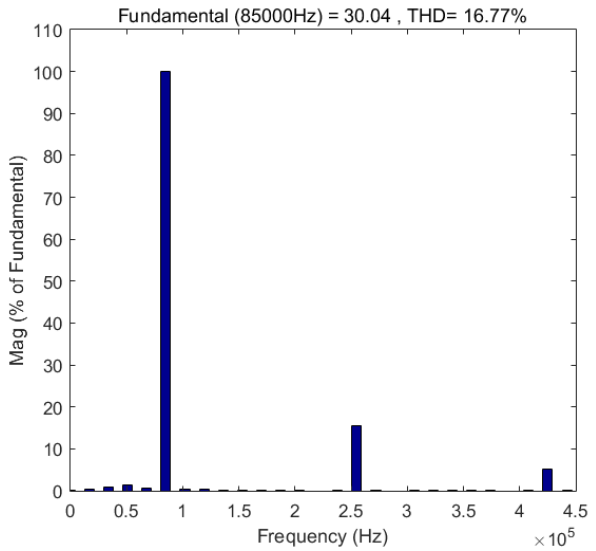

(c)

Figure 5. Simulink simulation results of $I_{f 1}$ harmonics under different $\sigma$ values: $(\mathbf{a}) \sigma=0.8 ;(\mathbf{b}) \sigma=1 ;(\mathbf{c}) \sigma=1.25$.

\section{The Realization of ZVS}

The MCRWPT system adopts full-bridge inverter. In practical application, to prevent the circuits of the upper and lower bridge arms from appearing directly and to avoid damage to the switching devices, enough dead time should be set for the switches of the upper and lower bridge arms to ensure the normal operation of the circuit when driving the switch tube of the full-bridge inverter. When the system operates in a completely resonant state, that is, the difference between the input voltage and the current is $0, \mathrm{ZVS}$ is difficult to achieve. To realize ZVS, the input impedance of the system must be inductive. From the perspective of parameter optimization design, in this study, we realized the inverter ZVS under a wide range of coupling coefficients and load changes.

\subsection{The Realization Conditions of ZVS}

For the case in which the system realizes ZVS, the waveform diagrams of the inverter drive signal, output voltage, and current are shown in Figure 6, and the commutation process is shown in Figure 7. The process of turning off $S_{1}$ and $S_{4}$, and turning on $S_{2}$ and $S_{3}$, are analyzed as follows.

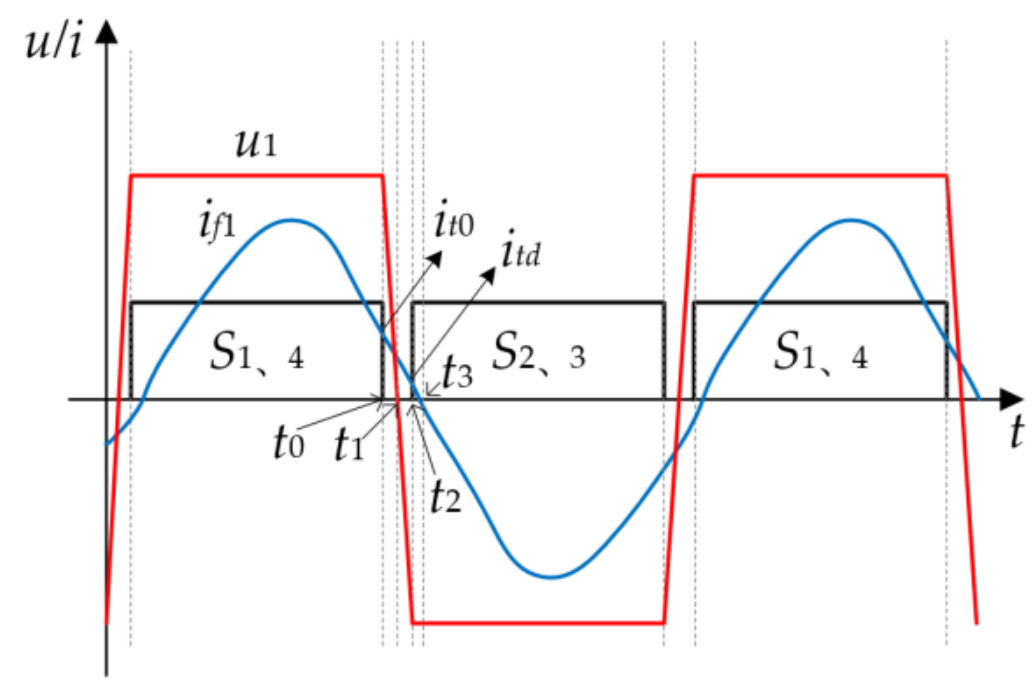

Figure 6. Timing diagram of the inverter drive signal, output voltage, and current under the ZVS condition. 


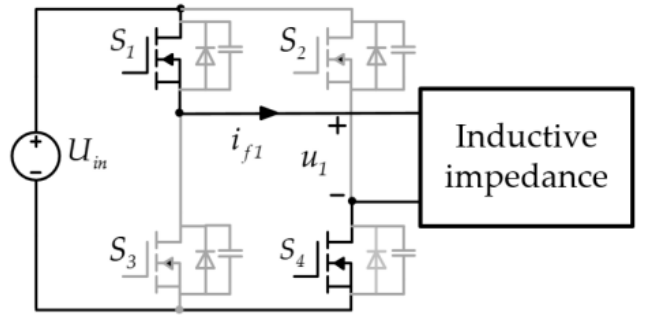

(a)

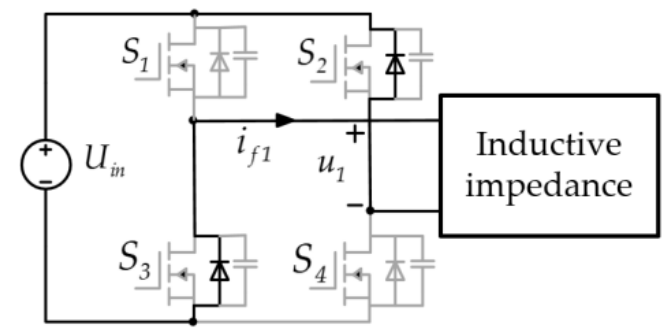

(c)

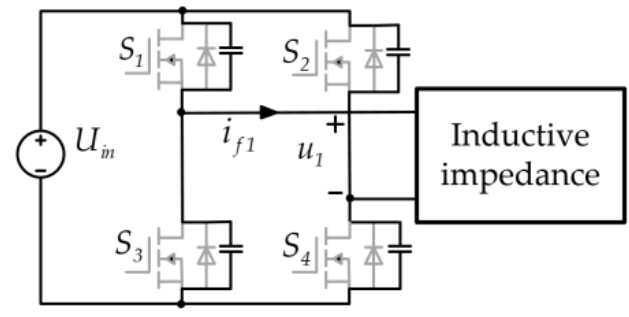

(b)

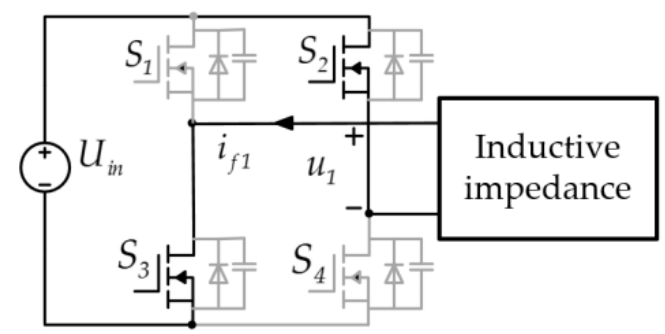

(d)

Figure 7. Phase conversion process of the inverter in the ZVS state: (a) $S_{1}$ and $S_{4}$ work normally; (b) capacitor $C_{\text {oss }}$ charge and discharge; (c) diode continuation; (d) $S_{2}$ and $S_{3}$ conduct.

Prior to $t_{0}, S_{1}$ and $S_{4}$ conduct, and $u_{1}$ is $U_{i n}$. At the stage of $t_{0}-t_{1}, S_{1}$ and $S_{4}$ are turned off, the inverter output current $i_{f 1}$ passes through the junction capacitance of the switch tube, the junction capacitance of $S_{1}$ and $S_{4}\left(C_{o s s}\right)$ charges, the junction capacitance of $S_{2}$ and $S_{3}$ discharges, and $u_{1}$ shows a linear decreasing trend. At the stage of $t_{1}-t_{2}$, the junction capacitors of $S_{2}$ and $S_{3}$ discharge completely, the voltage at both ends of $S_{2}$ and $S_{3}$ drops to zero, the current $i_{f 1}$ does not reverse, and the volume diodes of $S_{2}$ and $S_{3}$ continue to flow. At the moment of $t_{2}$, the driving signals of $S_{2}$ and $S_{3}$ arrive to realize ZVS. At the stage of $t_{2}-t_{3}, i_{f 1}$ reverses, $S_{2}$ and $S_{3}$ conduct, and $u_{1}$ is $-U_{i n}$. During this process, the dead time $t_{d}=t_{2}-t_{0}$, during which the current approximately linearly decreases, and the conditions for realizing ZVS of the inverter switch tube, are as follows:

$$
i_{t 0}+i_{t d}>\frac{4 C_{o s s} U_{i n}}{t_{d}}, i_{t d}>0
$$

where $i_{t d}$ is the dead zone ending current and $i_{t 0}$ is the shutdown current. When $C_{o s s}, U_{i n}$, and $t_{d}$ are determined, the implementation of ZVS is only related to $i_{t 0}$ and $i_{t d} . i_{t 0}$ and $i_{t d}$ are essentially the $i_{f 1}$, so it can be known from Equation (4) that the size of $i_{t 0}$ and $i_{t d}$ is related to the system coupling coefficient, load resistance value, and the compensation circuit element parameters. Therefore, in the case of a wide range of coupling coefficients and load resistances, ZVS can be realized by optimizing the component parameters so that $i_{t 0}$ and $i_{t d}$ always satisfy Equation (10).

\subsection{Design of Dead Time}

Setting a reasonable dead time is the key to realizing the ZVS inverter. If the dead time setting is too short, a short circuit of the upper and lower bridge arms of the inverter will occur; if the parasitic capacitor impulse current is too large, it may burn out the MOSFET. If the dead time too long, the inverter cannot realize ZVS and generate the impulse current. With the increase in dead time, the output voltage waveform of the inverter is worsened, affecting the transmission efficiency of the system. To ensure the optimal dead time of the inverter MOSFET to realize ZVS, the parasitic capacitor should be fully charged and discharged, and another branch MOSFET should be conducted before the end of the reverse parallel diode continuation current. Thus, the dead time $t_{d}$ should satisfy: 


$$
t_{c}+t_{o f f}<t_{d}<t_{D}
$$

where $t_{c}$ is the charge and discharge time of the parasitic capacitor, $t_{\text {off }}$ is the MOSFET turn-off time, and $t_{D}$ is the diode continuation time.

When the model of the MOSFET is determined, the $t_{\text {off }}$ time is determined. The charging and discharging time of the parasitic capacitor, $t_{c}$, is:

$$
t_{c}=C_{o s s} \frac{\sqrt{2}\left|Z_{i n}\right|}{\sin \theta}
$$

The diode continuation time, $t_{D}$, is:

$$
t_{D}=\frac{\theta}{180^{\circ}} \times \frac{T}{2}=\frac{\theta}{360^{\circ}} T
$$

where $T$ is the one switching period of the inverter. In practical application, considering that the time of the MOSFET turn-on and turn-off is prolonged due to heat, the optimal dead zone time $t_{d}$ should be relatively large.

\subsection{Analysis of the Influence of Resonant Circuit Parameters on Input Impedance Angle}

According to Equation (6), the input impedance expression of the compensation circuit is derived when the parameters of complete resonance and inductance, and capacitance, change:

$$
\left\{\begin{array}{l}
Z_{i n}=\frac{L_{f 2}}{\omega^{2} C_{f 1}{ }^{2} Z_{r}} \\
Z_{i n_{-} L_{f 1}}=\frac{\omega^{2} L_{f 1}{ }^{2}}{Z_{r}}-j \omega\left(L_{f 1}^{\prime}-L_{f 1}\right) \\
Z_{i n_{-} C_{f 1}}=\frac{\frac{Z_{r}}{\omega C_{f 1}^{\prime}}+j\left[\frac{Z_{r}{ }^{2}}{\omega}\left(\frac{1}{C_{f 1}}-\frac{1}{C_{f 1}^{\prime}}\right)+\frac{1}{\omega^{3} C_{f 1}}\left(\frac{1}{C_{f 1}{ }^{2}}+\frac{2}{C_{f 1}^{\prime}}-\frac{3}{C_{f 1} C_{f 1}^{\prime}}\right)\right]}{Z_{r}^{2}+\left(\frac{1}{\omega C_{f 1}}-\frac{1}{\omega C_{f 1}^{\prime}}\right)^{2}} \\
Z_{i n_{-} C_{1}}=\frac{C_{1}^{\prime}\left(\omega^{2} L_{p} C_{1}-1\right)\left[Z_{r} \omega^{2} C_{1} C_{f 1}+j \omega C_{f 1}\left(C_{1}-C_{1}^{\prime}\right)\right]}{\omega^{2} C_{f 1}{ }^{2}\left(C_{1}-C_{1}^{\prime}\right)^{2}+\left(Z_{r} \omega^{2} C_{1} C_{f 1} C_{1}^{\prime}\right)^{2}} \\
Z_{i n_{-} L_{f 2}}=\frac{L_{f 2}\left[R_{e q}+j \omega\left(L_{f 2}-L_{f 2}^{\prime}\right)\right]}{\omega^{2} M^{2} C_{f 1}{ }^{2}\left[R_{e q}{ }^{2}+\omega^{2}\left(L_{f 2}-L_{f 2}^{\prime}\right)^{2}\right]} \\
Z_{i n_{-} C_{f 2}}=\frac{\frac{R_{e q}}{\omega C_{f 2}^{\prime}{ }^{2}}+j\left[\frac{R_{e q}{ }^{2}}{\omega}\left(\frac{1}{C_{f 2}}-\frac{1}{C_{f 2}^{\prime}}\right)+\frac{1}{\omega^{3} C_{f 2} 2}\left(\frac{1}{C_{f 2}{ }^{2}}+\frac{2}{C_{f 2}^{\prime}{ }^{2}}-\frac{3}{C_{f 2} C_{f 2}^{\prime}}\right)\right]}{\omega^{4} M^{2} C_{f 1}{ }^{2}\left[R_{e q}{ }^{2}+\left(\frac{1}{\omega C_{f 2}}-\frac{1}{\omega C_{f 2}^{\prime}}\right)^{2}\right]} \\
Z_{i n n_{-} C_{2}}=\frac{C_{2}^{\prime} C_{2}+j \omega\left(C_{2}^{\prime}-C_{2}\right) C_{f 2}{ }^{2} R_{e q}}{\omega^{6} M^{2} C_{f 1}{ }^{2} C_{f 1}{ }^{2} C_{2}^{\prime} C_{2} R_{e q}}
\end{array}\right.
$$

where $Z_{r}=w^{2} M^{2} C_{f 2} R_{e q} / L_{f 2}, C_{1}{ }^{\prime}, C_{f 1}{ }^{\prime}, L_{f 1}{ }^{\prime}, C_{2}{ }^{\prime}, C_{f 2}{ }^{\prime}$, and $L_{f 2}{ }^{\prime}$ are the changed circuit component parameter values.

The variation range of the component parameters is set from 0.8 to 1.2. Combined with Tables 2 and 3, and Equation (14), the curve of the circuit input impedance angle, for component parameters under different loads, can be fitted, as shown in Figure 8. It can be seen from Figure 8 that, with the change in component parameters, the circuit input impedance angle changes in inductance, resistance, and capacitance. By contrast, changing the values of $C_{1}$ and $C_{2}$ has a more obvious effect on the impedance angle. As $C_{1}$ and $C_{2}$ change from small to large, they have the opposite effect on the impedance angle. However, according to Equation (4), changing $C_{2}$ affects the constant current output characteristics of the secondary side. Therefore, ZVS is finally realized by changing the value of parameter $C_{1}$. 


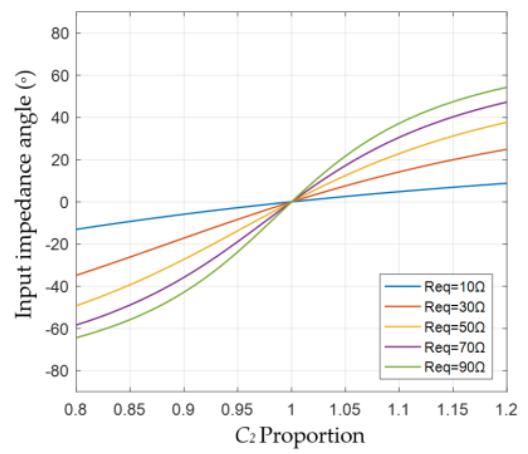

(a)

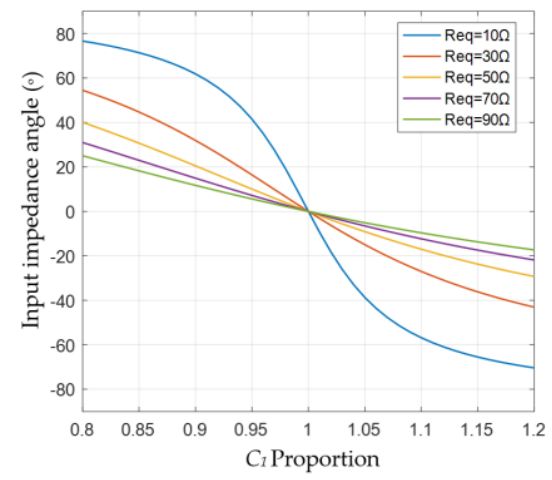

(d)

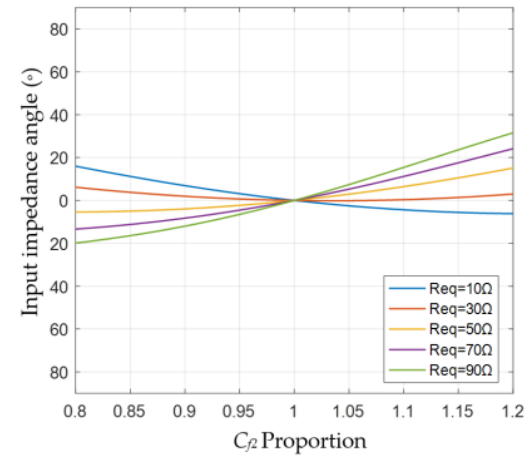

(b)

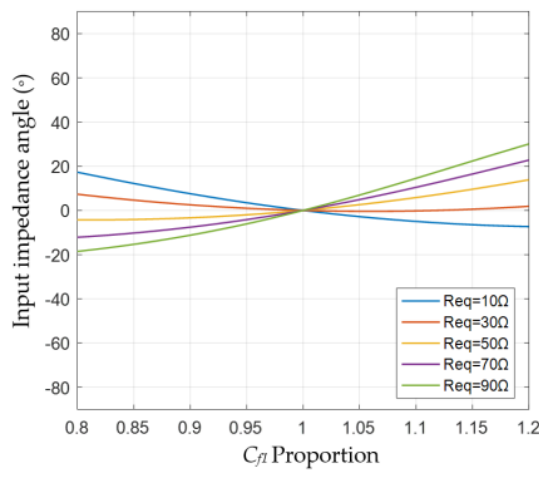

(e)

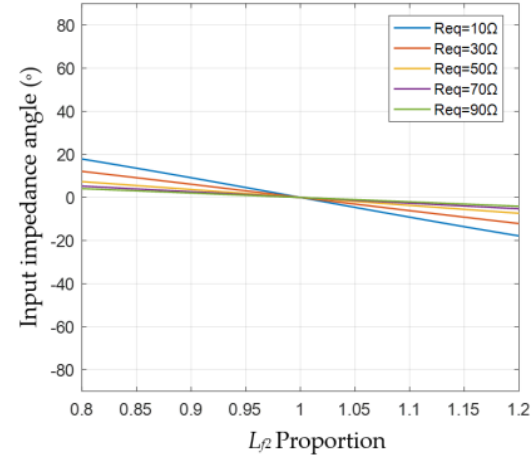

(c)

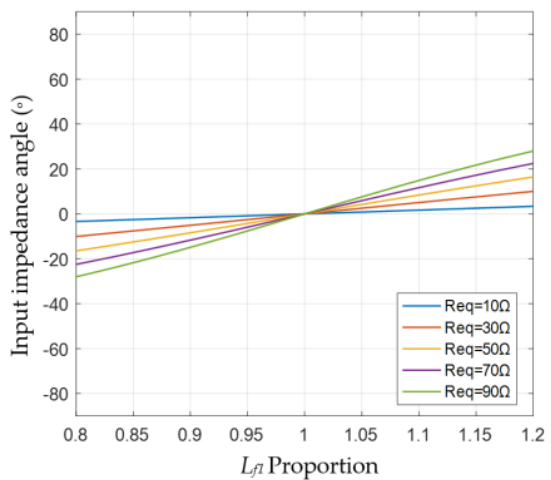

(f)

Figure 8. Variation curve of the input impedance angle with component parameters of the DLCC circuit (different loads): (a) $C_{2} ;(\mathbf{b}) C_{f 2} ;(\mathbf{c}) L_{f 2} ;$ (d) $C_{1} ;(\mathbf{e}) C_{f 2} ;(\mathbf{f}) L_{f 2}$.

We can take the equivalent resistance $R_{e q}=30 \Omega$ to fit the curve of the change in the circuit input impedance angle with the change in $C_{1}$ under different coupling coefficients, as shown in Figure 9. According to Figures $8 \mathrm{~d}$ and 9 , when the value of $C_{1}$ is determined (excluding the ratio of 1), with the increase in the coupling coefficient and the load value, the change in the input impedance angle steadily becomes smaller. Therefore, as long as the value of $C_{1}$ satisfying ZVS is determined in the case of the maximum coupling coefficient and the maximum load value, ZVS in the full range of coupling coefficients and loads can be realized.

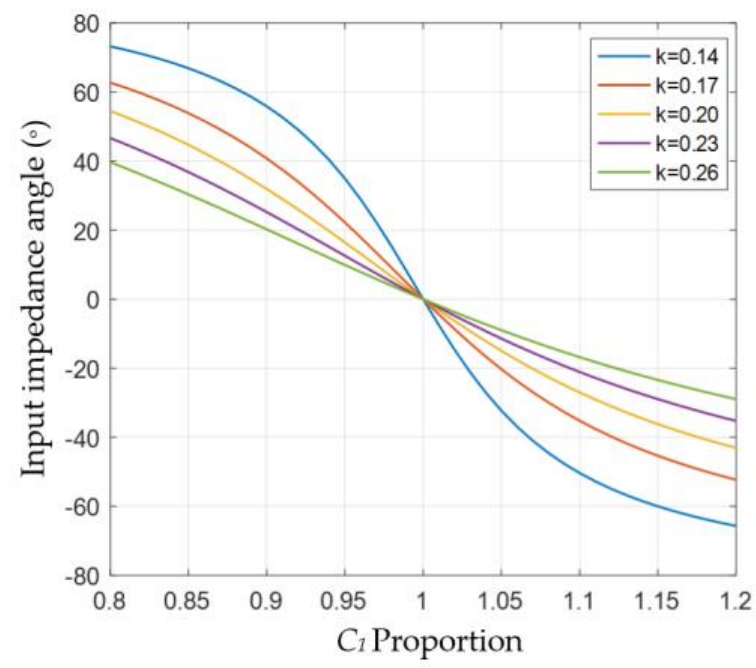

Figure 9. Variation curve of the input impedance angle with $C_{1}$ of the DLCC circuit (with different coupling coefficients). 
According to Equation (10), the value of $i_{t 0}+i_{t d}$ is determined by $C_{o s s}, U_{i n}$, and $t_{d}$. Therefore, the relationship between $i_{t 0}, i_{t d}$, and $C_{1}$ needs to be clarified to obtain the optimized value of $C_{1}$. The high-order harmonics of the current $i_{f 1}$ are ignored. The phase difference between the fundamental voltage of the compensation circuit and the input fundamental voltage is defined as $\alpha$, and the expressions of $i_{t 0}$ and $i_{t d}$ are obtained by combining with Equation (1).

$$
\begin{gathered}
i_{t 0}=\sqrt{2} I_{f 1} \sin (\pi+\alpha) \\
i_{t d}=\sqrt{2} I_{f 1} \sin \left(\omega t_{d}+\pi+\alpha\right) \\
\tan \alpha=\frac{\left(C_{1}-C^{\prime}\right)}{Z_{r} \omega C_{1}} \\
I_{f 1}=\sqrt{\left(\omega^{6} M^{2} C_{f 1}{ }^{2} C_{f 2}{ }^{2} R_{e q} U_{1}\right)^{2}+\left[\omega C_{f 1}{ }^{2} U_{1}\left(\frac{1}{C^{\prime} 1}-\frac{1}{C_{1}}\right)^{2}\right.}
\end{gathered}
$$

Therefore, according to Equations (10) and (15)-(18), the value of $C_{1}$ satisfying ZVS can be calculated.

\subsection{Parameters Optimization Control Strategy}

According to the analysis in the above section, after optimizing the basic parameters of the WPT system, when the load and coupling coefficient change, the inverter can theoretically be guaranteed to work in the ZVS state at all times. However, due to the progress in the wireless charging process of electric vehicles, the temperature of the magnetically coupled mechanism and compensation circuit will inevitably rise, and the system parameters will change. This will result in interference in the inverter output voltage and the current waveform. Although this change will not have a significant impact on the system, it is likely to change the working state of the inverter ZVS. When the MCRWPT system works normally, the circuit parameters cannot be changed. It can be seen from Equations (10) and (15)-(18) that the working state of the inverter can only be adjusted by changing the dead time $t_{d}$ and frequency $f$ of the inverter.

Because the output voltage and current of the inverter will not mutate, the dynamic adjustment of the dead zone time does not require a high speed. Thus, the control is carried out by adjusting the dead zone and frequency with a fixed-length step. The MCRWPT system control block diagram and parameter optimization control flow chart are shown in Figures 10 and 11, respectively.

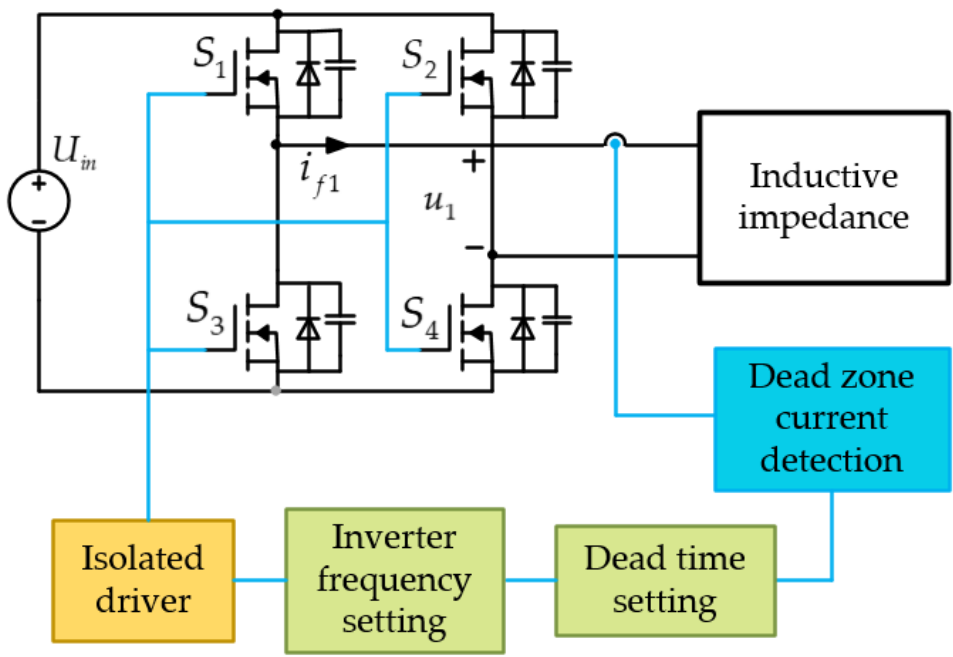

Figure 10. MCRWPT system control block diagram. 


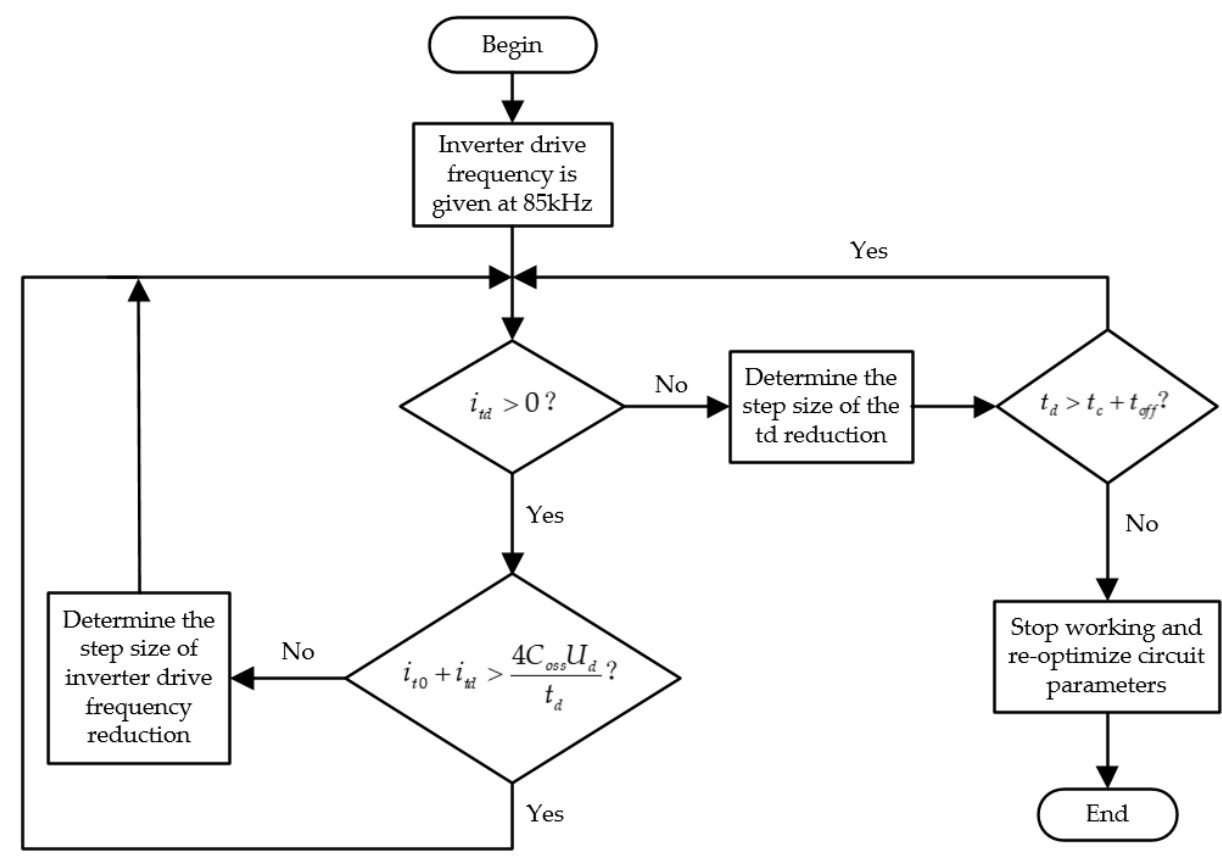

Figure 11. MCRWPT system parameter optimization control flow chart.

\section{Simulation and Experimental Verification}

\subsection{Analysis of Simulation Results}

According to the stress analysis of the compensating circuit elements and the effect of harmonic suppression, the value of $\sigma$ is 1.25. The basic parameters of the circuit are obtained from Tables 2 and 3, and the output power level is 7.7 KW. The IMZ120R045M1 MOSFET of Infineon was selected. According to the device manual, the $C_{\text {oss }}$ is $1100 \mathrm{pF}$ and the dead zone time is set at $400 \mathrm{~ns}$. From Equation (10), we can obtain $i_{t 0}+i_{t d}>4.4 \mathrm{~A}$. The high-frequency component of the current is not considered in Equations (15) and (16) in this paper, but the existence of the high-frequency component will inevitably affect the accuracy of the ZVS implementation. A margin can be set to ensure the sum of the current is $6 \mathrm{~A}$. According to the above analysis, as long as the system can realize ZVS at the maximum coupling coefficient and the maximum output voltage, it can guarantee the realization of ZVS at all times. Combined with the above equations, the curves of $i_{t 0}$ and $i_{t d}$ with $C_{1}$ were obtained under the conditions of the maximum coupling coefficient $(0.2)$ and the maximum output voltage (450 V), as shown in Figure 12.

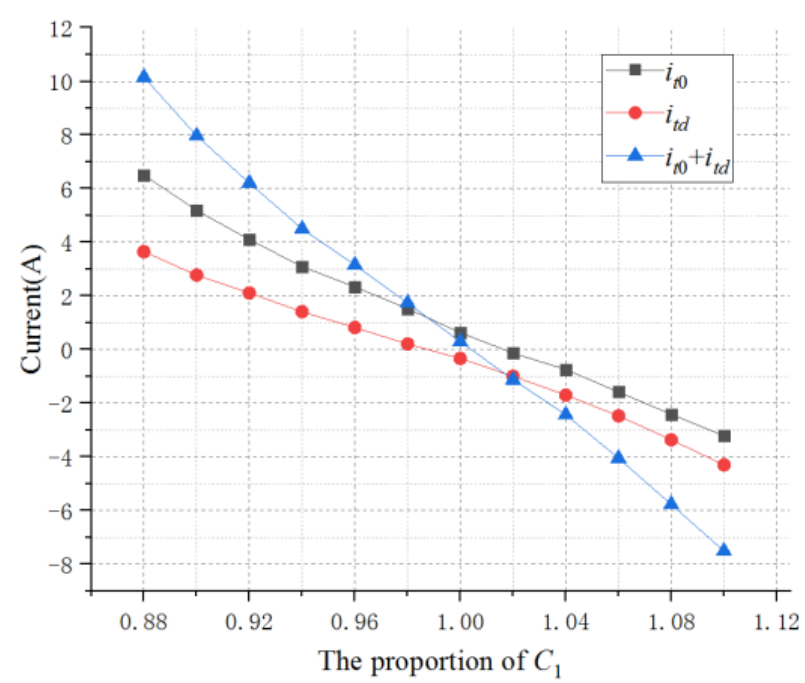

Figure 12. Curve of $i_{t 0}$ and $i_{t d}$ changing with $C_{1}(k=0.2, U o=450 \mathrm{~V})$. 
As can be seen from the figure, when $C_{1}{ }^{\prime}<0.99 C_{1}, i_{t d}$ is always greater than 0 ; when $C_{1}{ }^{\prime}<0.92 C_{1}, i_{t 0}+i_{t d}$ is always greater than $6 \mathrm{~A}$. Therefore, to realize ZVS, the optimal value of $C_{1}{ }^{\prime}$ is $0.92 C_{1}(141.65 \mathrm{nF})$.

A simulation circuit was built in Simulink. When $k=0.2$ and $U_{0}=450 \mathrm{~V}, C_{1}{ }^{\prime}$ was set to $0.92 C_{1}, C_{1}$, and $1.08 C_{1}$. The output voltage and current curves of the inverter and the opening of the MOSFET (taking $S_{3}$ as an example) were obtained under the three conditions of realizing ZVS (input impedance is inductive), PRS (input impedance is pure resistance), and capacitive input impedance. The results are shown in Figures 13-15. When the inverter implements ZVS, the voltage $u_{1}$ phase leads $i_{f 1}$. The turn-off current $i_{t 0}$ is $4.84 \mathrm{~A}$, the dead-zone ending current $i_{t d}$ is $1.68 \mathrm{~A}$, and the sum of the two is $6.52 \mathrm{~A}$. The MOSFET has good breaking characteristics. When the system is fully resonant, $u_{1}$ and $i_{f 1}$ are in phase and the voltage oscillates during the dead time. When the MOSFET cannot achieve ZVS, switching loss occurs. When the input impedance of the system is capacitive, the phase of $u_{1}$ lags behind $i_{f 1}$, and both $i_{t 0}$ and $i_{t d}$ are less than zero. When the $S_{3}$ drive signal arrives, the voltage at both ends of $S_{3}$ is greater than zero, so there is also opening loss in $S_{3}$.

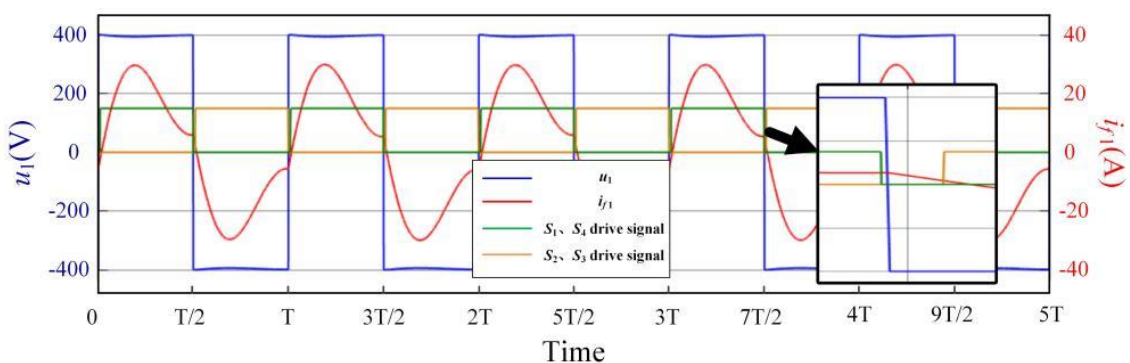

(a)

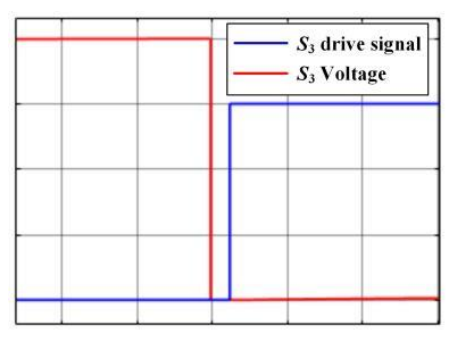

(b)

Figure 13. Output characteristics of the inverter in ZVS: (a) voltage and current waveform; (b) ZVS.

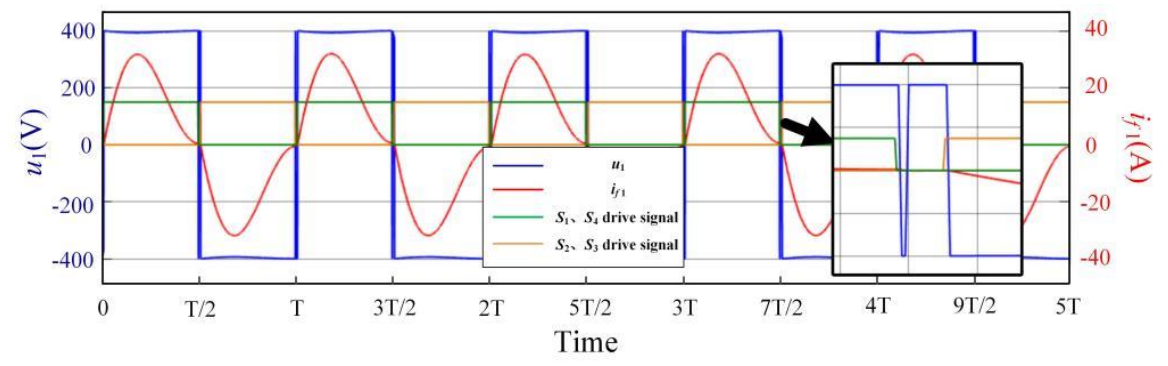

(a)

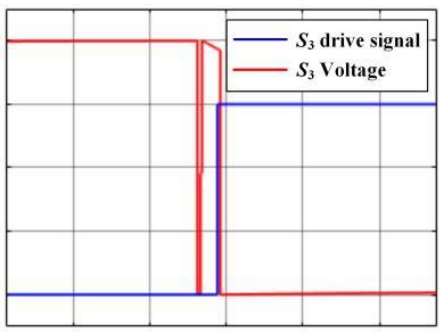

(b)

Figure 14. Output characteristics of the inverter in PRS: (a) voltage and current waveform; (b) no ZVS.

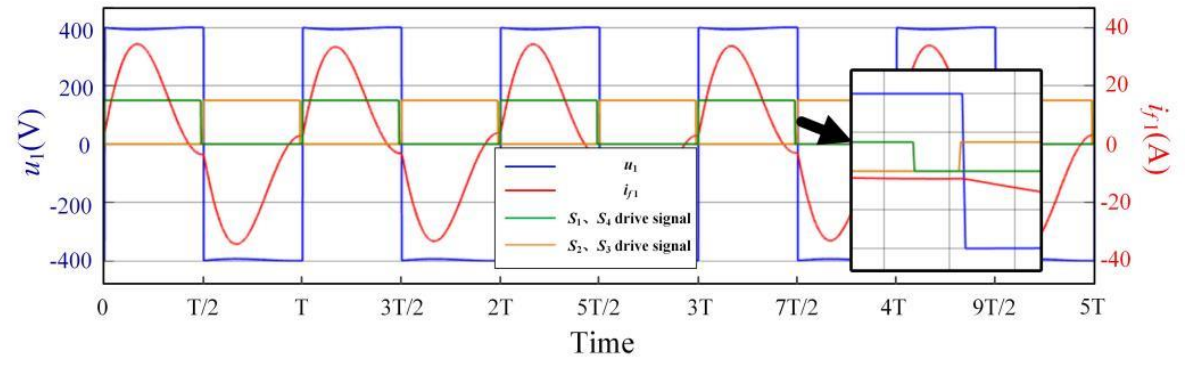

(a)

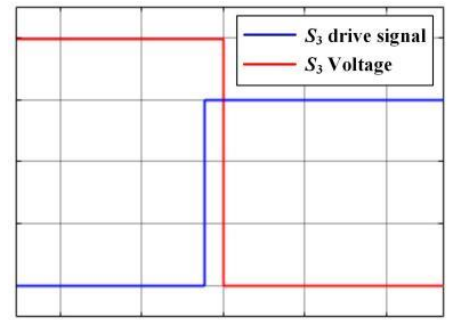

(b)

Figure 15. Output characteristics of the inverter when the input impedance is capacitive: (a) voltage and current waveform; (b) no ZVS. 


\subsection{Analysis of Experimental Results}

Under the parameter adjustment control strategy proposed in this paper, the step size of the dead zone time reduction is set as $20 \mathrm{~ns}$, and the step size of the frequency reduction is set as $0.2 \mathrm{kHz}$. According to the simulation parameters, an experimental platform was constructed, as shown in Figure 16. According to the current flow direction, the system comprised a DC power supply, an inverter controller, a resonant circuit, a magnetically coupled mechanism, a rectifier filter circuit, and an electronic load.

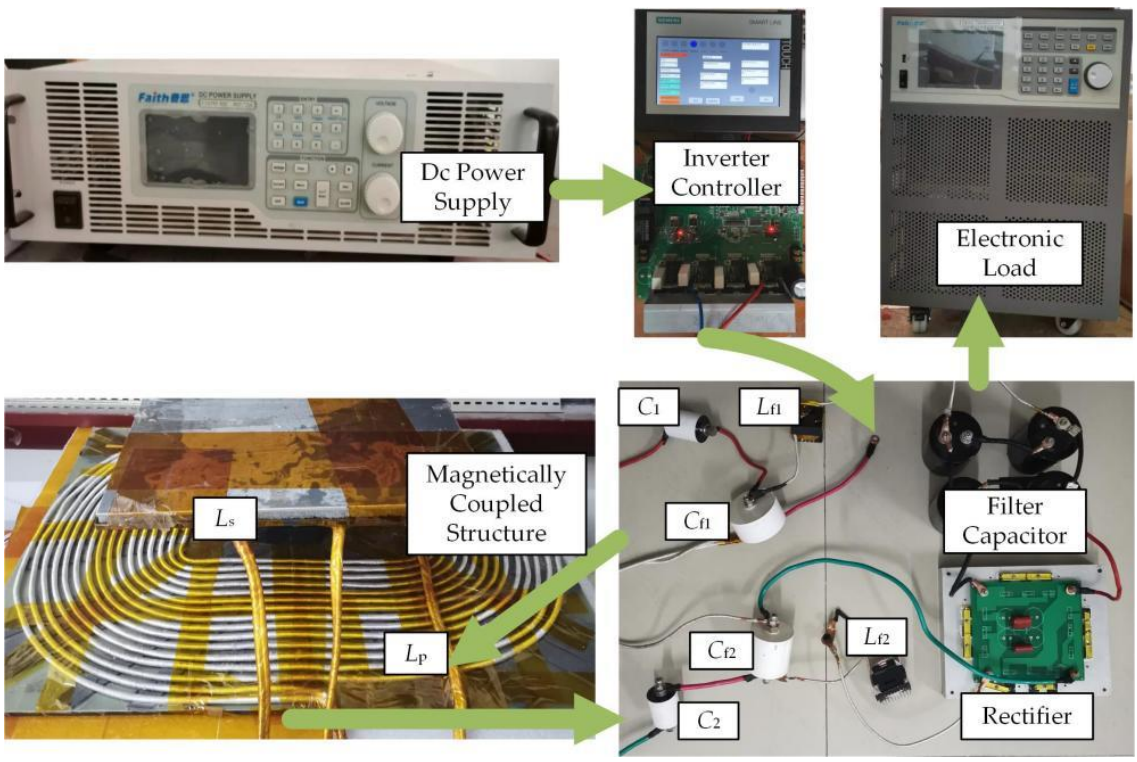

Figure 16. The MCRWPT system experiment platform.

Under two conditions of the system, i.e., PRS and ZVS, the wireless charging experiment with maximum output power of $7.7 \mathrm{~kW}$ was completed. Figure 17 compares the experimental waveforms of PRS and ZVS at different power levels. It was found that the turn-off current and dead-zone ending current in the ZVS state are larger, and the switching performance is better in the dead-zone time.

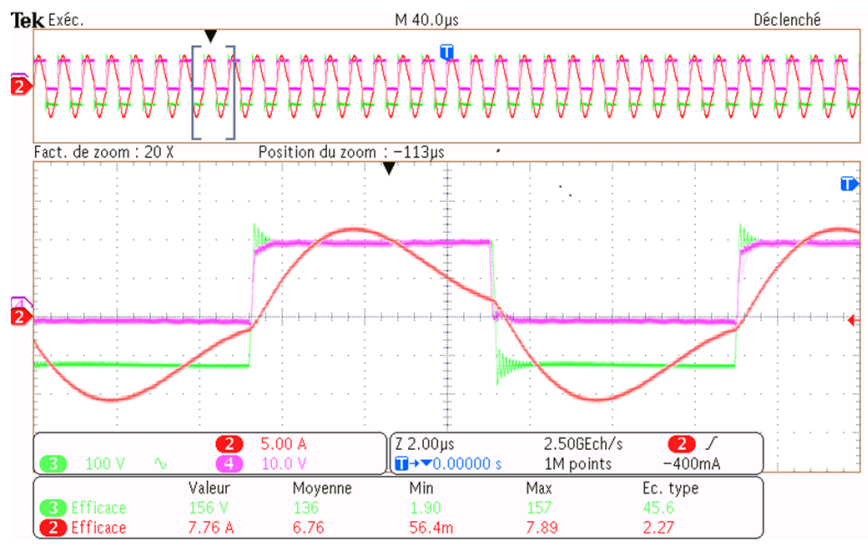

(a)

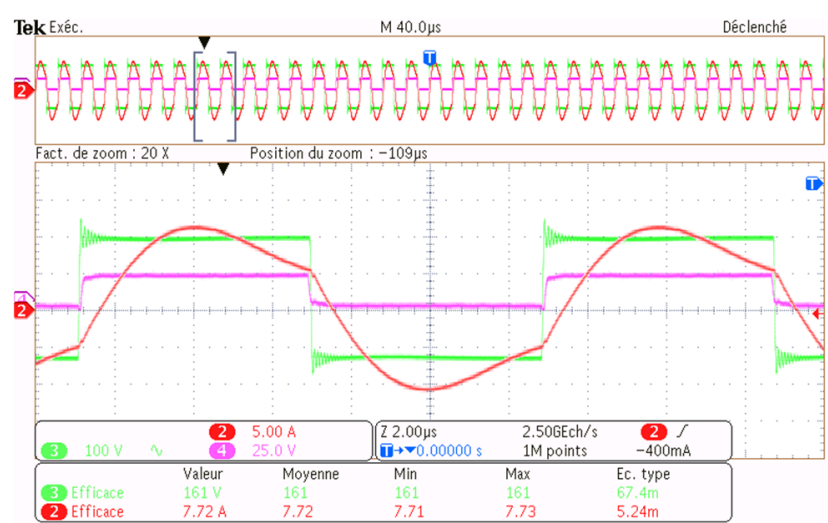

(b)

Figure 17. Cont. 


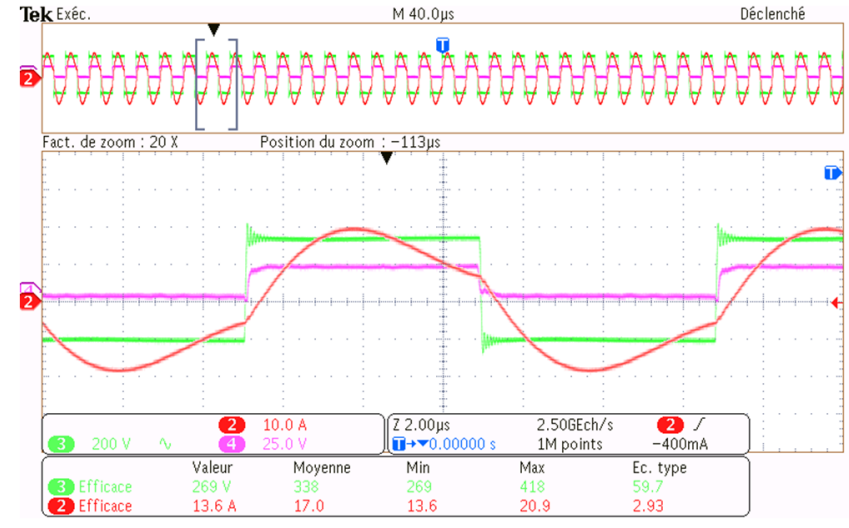

(c)

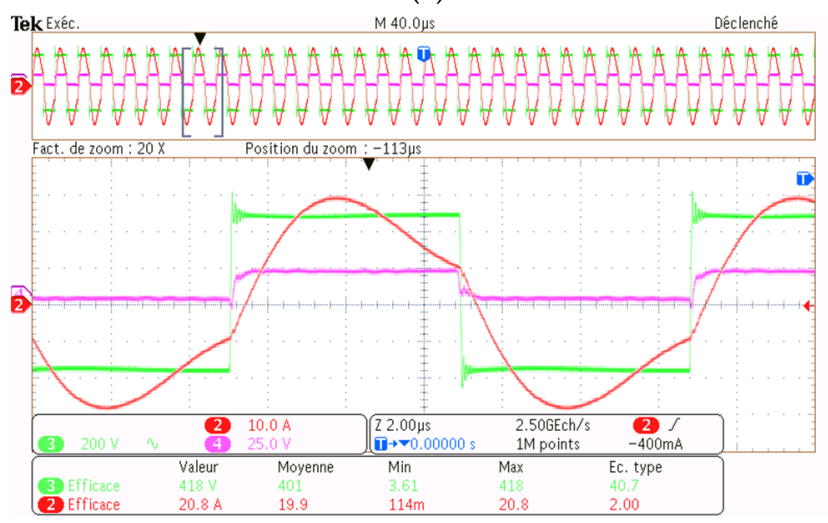

(e)

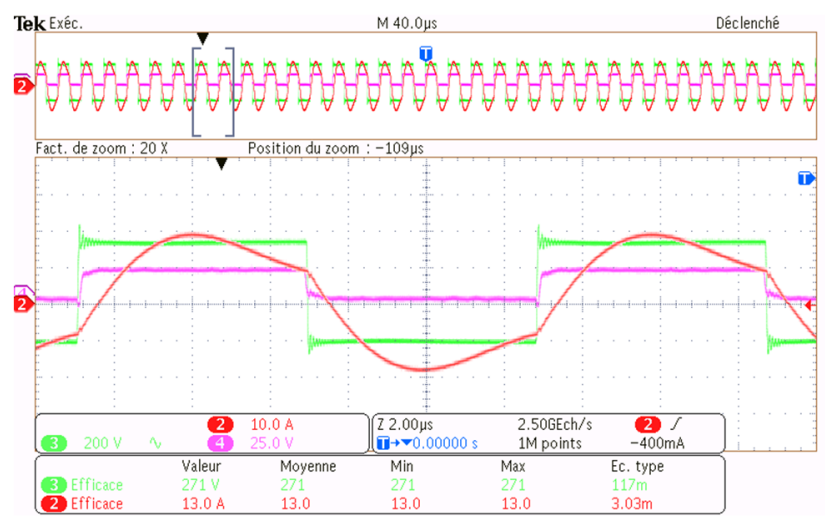

(d)

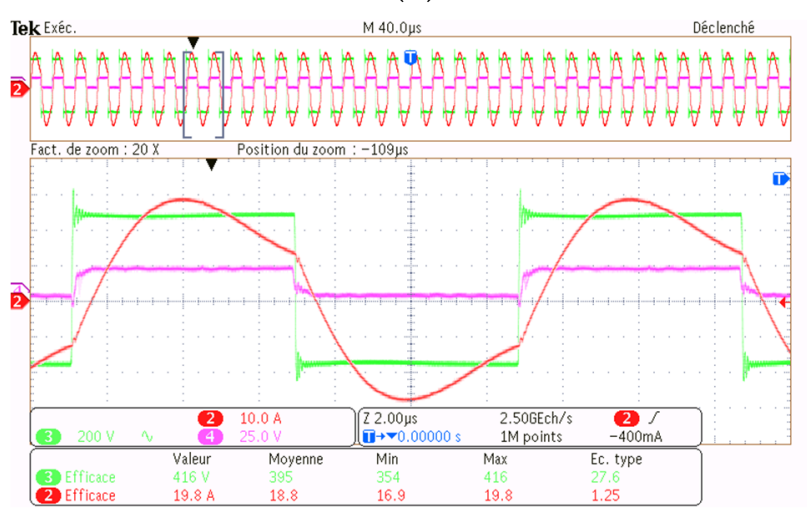

(f)

Figure 17. Comparison of experimental waveforms between PRS and ZVS at different power levels: (a) $1.1 \mathrm{~kW}$ (PRS); (b) 1.1 kW (ZVS); (c) $3.3 \mathrm{~kW}$ (PRS); (d) $3.3 \mathrm{~kW} \mathrm{(ZVS);} \mathrm{(e)} 7.7 \mathrm{~kW}$ (PRS); (f) $7.7 \mathrm{~kW} \mathrm{(ZVS).}$

Figure 18 shows the variation curve of the output power and efficiency with the input power of the system under PRS and ZVS conditions. According to the results in the figure, the system efficiency shows an upward trend with the increase in power level. Under the same input power condition, compared with PRS, the system implementing ZVS has higher output power and higher efficiency. Under different power levels, the average efficiency of PRS is $90.87 \%$, and the average efficiency of ZVS is $91.86 \%$, thus indicating an improvement in ZVS efficiency of about $1 \%$.

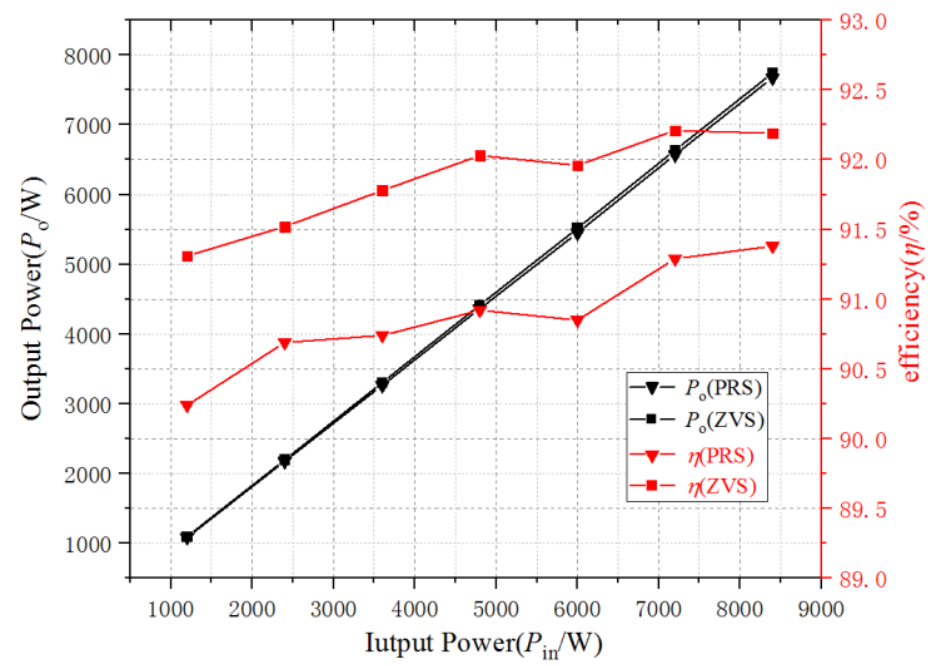

Figure 18. Variation in the output power and efficiency of the system with the input power. 


\section{Conclusions}

The MCRWPT system studied in this paper has a high power grade, and the DLCC topology has better anti-migration and power transmission stability. Based on the DLCC topology, this study proposed a parameter optimization control strategy based on frequency and dead time to improve power transmission efficiency. Without changing the circuit structure, ZVS in a wide range of voltage classes was realized. This method comprehensively considers the influence of parameter changes on the implementation of ZVS, can be simply controlled, and overcomes the shortcomings of the ZVS implementation method, as noted in Section 1.

First, a DLCC equivalent circuit model was established, and the expressions of output voltage, current, and input impedance were derived. Second, five sets of component parameter values were obtained according to the changes in the primary and secondary side compensation inductance values. The suppression effect of the circuit component stress and high-frequency harmonics under different parameters was analyzed, and the optimal compensation inductance value was determined. Third, the realization conditions of ZVS were analyzed, the best dead time of the MOSFET was determined, and the change in the system input impedance angle with different component parameter values was obtained. The relationship between the inverter output current and the capacitor $C_{1}$ was established, and the optimal capacitor value was determined through simulation. Finally, a parameter optimization control strategy to achieve ZVS was proposed. Under different output power levels, the average efficiency of the PRS was $90.87 \%$, the average efficiency of ZVS was $91.86 \%$, indicating an increase in efficiency of about $1 \%$.

Therefore, the parameter optimization strategy of the DLCC MCRWPT system based on ZVS can reduce the power loss of the MOSFET, effectively improve the charging efficiency, and promote the development of WPT technology. This strategy can be applied to high-power WPT systems, such as robots and electric vehicles, and has certain practical significance.

Author Contributions: Conceptualization, G.F. and Z.L.; formal analysis, G.F., S.S. and X.L.; funding acquisition, Z.L.; investigation, Z.L. and G.F.; methodology, G.F. and R.D.; project administration, Z.L. and Y.H.; resources, Z.L. and Y.H.; software, G.F., X.L. and Y.H.; supervision, Z.L. and A.Y.; validation, G.F., S.S. and R.D.; writing—original draft, G.F.; writing—review and editing, G.F. All authors have read and agreed to the published version of the manuscript.

Funding: This research was funded by the Science and Technology Research Project of Shandong Province under Grant No. 2019GGX104080.

Conflicts of Interest: The authors declare no conflict of interest.

\section{References}

1. Zhang, Z.; Pang, H.; Georgiadis, A.; Cecati, C. Wireless power transfer-An overview. IEEE Trans. Ind. Electron. 2019, 66, 1044-1058. [CrossRef]

2. Ahmad, A.; Alam, M.S.; Chabaan, R. A Comprehensive Review of Wireless Charging Technologies for Electric Vehicles. IEEE Trans. Transp. Electrif. 2018, 4, 38-63. [CrossRef]

3. Feng, H.; Tavakoli, R.; Onar, O.C.; Pantic, Z. Advances in High-Power Wireless Charging Systems: Overview and Design Considerations. IEEE Trans. Transp. Electrif. 2020, 6, 886-919. [CrossRef]

4. Ziyang, L.; Xi, Z.; Zhimin, Z.; Zhe, L. Dead-time Optimization of Resonant Wireless Charging Switches Considering System Performance Improvement. Autom. Electr. Power Syst. 2017, 41, 176-181.

5. Jin, C.; Xusheng, W.; Fengge, H.; Pan, S.; Jun, S. Stability Analysis and Efficiency Optimization Design of Bilateral LCC Inductively Coupled Radio Energy Transmission System. Trans. China Electrotech. Soc. 2020, 35, 355-362.

6. Na, N.; Huynh, T.; Badawy, M.O. Design of a Feedback Controlled Dual Sided LCC Converter to Achieve ZVS for Electric Vehicle Wireless Charging Applications. In Proceedings of the IECON 2019-45th Annual Conference of the IEEE Industrial Electronics Society, Lisbon, Portugal, 14-17 October 2019; pp. 2658-2663.

7. Xueliang, H.; Wei, W.; Linlin, T. Research Status and Application Prospect of Magnetic Coupled Resonant Radio Energy Transmission Technology. Autom. Electr. Power Syst. 2017, 41, 2-14. 
8. Deng, J.; Fei, L.; Li, W.; Ruiqing, M.; Mi, C. ZVS double-side LCC compensated resonant inverter with magnetic integration for electric vehicle wireless charger. In Proceedings of the 2015 IEEE Applied Power Electronics Conference and Exposition (APEC), Charlotte, NC, USA, 15-19 March 2015; pp. 1131-1136.

9. Hu, H.; Cai, T.; Duan, S.; Zhang, X.; Niu, J.; Feng, H. An Optimal Variable Frequency Phase Shift Control Strategy for ZVS Operation within Wide Power Range in IPT Systems. IEEE Trans. Power Electron. 2020, 35, 5517-5530. [CrossRef]

10. Jiang, Y.; Wang, L.; Wang, Y.; Liu, J.; Li, X.; Ning, G. Analysis, Design, and Implementation of Accurate ZVS Angle Control for EV Battery Charging in Wireless High-Power Transfer. IEEE Trans. Ind. Electron. 2019, 66, 4075-4085. [CrossRef]

11. Zhang, X.; Cai, T.; Duan, S.; Feng, H.; Hu, H.; Niu, J.; Chen, C. A Control Strategy for Efficiency Optimization and Wide ZVS Operation Range in Bidirectional Inductive Power Transfer System. IEEE Trans. Ind. Electron. 2019, 66, 5958-5969. [CrossRef]

12. Yuwang, Z.; Lifang, W.; Yanjie, G. Design and Research of Phase Shift Control ZVS for Wireless Energy Transmission System. Power Electron. 2019, 53, 97-100.

13. Jia, H.; Qianhong, C.; Siu, C.W.; Chi, K.T.; Xinbo, R. Analysis and Control of Series/Series-Parallel Compensated Resonant Converter for Contactless Power Transfer. IEEE J. Emerg. Sel. Top. Power Electron. 2015, 3, 124-136. [CrossRef]

14. Shenqin, Y.; Li, H.; Pan, S.; Xusheng, W. Research on Parameter Design Method of Bilateral LCCL Radio Energy Transmission System. Ship Electr. Technol. 2019, 39, 17-21.

15. Xin, D.; Yue, S. An Accurate Frequency Tracking Method Based on Short Current Detection for Inductive Power Transfer System. IEEE Trans. Ind. Electron. 2014, 61, 776-783.

16. Li, H.; Wang, K.; Fang, J.; Yi, T. Pulse Density Modulated ZVS Full-Bridge Converters for Wireless Power Transfer Systems. IEEE Trans. Power Electron. 2019, 34, 369-377. [CrossRef]

17. Kavimandan, U.D.; Mahajan, S.M.; Van Neste, C.W. Analysis and Demonstration of a Dynamic ZVS Angle Control Using a Tuning Capacitor in a Wireless Power Transfer System. IEEE J. Emerg. Sel. Top. Power Electron. 2021, 9, 1876-1890. [CrossRef]

18. Yang, C.; Yang, N.; Qiao, L.; He, Z.; Mai, R. New parameter tuning method for LCC/LCC compensated IPT system with constant voltage output based on LC resonance principles. IET Power Electron. 2019, 12, 2466-2474.

19. Li, S.; Li, W.; Deng, J.; Nguyen, T.D.; Mi, C.C. A Double-Sided LCC Compensation Network and Its Tuning Method for Wireless Power Transfer. IEEE Trans. Veh. Technol. 2015, 64, 2261-2273. [CrossRef]

20. Chen, Y.; Zhang, H.; Shin, C.S.; Jo, C.H.; Park, S.J.; Kim, D.H. An Efficiency Optimization-Based Asymmetric Tuning Method of Double-Sided LCC Compensated WPT System for Electric Vehicles. IEEE Trans. Power Electron. 2020, 35, 11475-11487. [CrossRef] 